\title{
Level of selenoprotein transcripts in peripheral leukocytes of patients with bladder cancer and healthy individuals
}

\author{
Edyta Reszka1,*, Jolanta Gromadzinska', Ewa \\ Jablonska ${ }^{1}$, Wojciech Wasowicz ${ }^{1}$, Zbigniew \\ Jablonowski ${ }^{2}$ and Marek Sosnowski ${ }^{2}$ \\ ${ }^{1}$ Department of Toxicology and Carcinogenesis, \\ Nofer Institute of Occupational Medicine, Lodz, \\ Poland \\ ${ }^{2}$ Department of Urology, Medical University, Lodz, \\ Poland
}

\begin{abstract}
Background: Low concentrations of selenium (Se) in humans have been associated with risk of cancer. Selenoprotein mRNAs can potentially be regulated by Se status.

Methods: Se status, GPX1 Pro198Leu and Sep15 1125G/A genetic polymorphism and human (h)GPX1, $h G P x 3, h S e p 15$ and $h S e P 1$ transcript levels in peripheral leukocytes of 33 males with bladder cancer and 47 healthy male controls were analysed.

Results: All the subjects expressed detectable selenoprotein mRNA concentrations in leukocytes. Significantly lower expression of $h G P x 1, h G P \times 3, h$ Sep 15 and $h \mathrm{SeP} 1$ in leukocytes of bladder cancer patients compared to controls was observed. $h G P x 1, h G P \times 3$ and $h$ Sep 15 expression was significantly lower in non-smokers in the control group compared with smokers in the control group. A positive relationship between expression of all studied genes was also observed in non-smoking controls. Expression of $h G P x 3$ and $h$ Sep 15 gradually increased with tumour grade in patients with cancer. We did not find any association between selenoprotein mRNA levels, Se status and selenoprotein genetic polymorphism.

Conclusions: This study showed significant downregulation of $h G P \times 1, h G P \times 3, h S e p 15$ and $h S e P 1$ mRNA levels in leukocytes of patients with bladder cancer compared to controls. Selenoprotein transcript levels in circulating leukocytes of patients with bladder cancer and controls revealed no potential impact of Se status on selenoprotein expression.

Clin Chem Lab Med 2009;47:1125-32.
\end{abstract}

Keywords: bladder cancer; genetic polymorphism; leukocytes; real-time PCR; selenoproteins.

\footnotetext{
*Corresponding author: Dr. Edyta Reszka, Department of Toxicology and Carcinogenesis, Nofer Institute of Occupational Medicine, Teresy 8, 91-348 Lodz, Poland Phone: + 484263146 27, Fax: +48 4265683 31, E-mail: edyta@imp.lodz.pl

Received March 31, 2009; accepted June 26, 2009
}

\section{Introduction}

Bladder cancer is the seventh most common cancer in men in the world, and fourth most common in Poland. The incidence is higher in Polish males than in males from Central and Eastern European countries, but similar to that observed in Western and Southern Europe and the US (1). Well known risk factors for bladder cancer include tobacco smoking, occupational exposure to aromatic amines from rubber or paint and chronic infections with schistosoma haematobium. Some additional risk factors, such as diet and nutritional habits have also been considered (2).

Selenium (Se) is a dietary trace element that is essential for human health (3). Low Se concentrations measured in blood, toenails and hair have been associated with lung, prostate and colorectal cancer (4), although epidemiological studies on Se status and bladder cancer risk showed contradictory results (5). One of the proposed anticancer mechanisms of Se suggests that there are antioxidative properties of selenoproteins. Se, genetically encoded as the $21 \mathrm{st}$ aminoacid selenocysteine, is reportedly present at the active sites of 25 selenoproteins in humans, including five Se-dependent glutathione peroxidases: cytosolic glutathione peroxidase (GPx1), extracellular plasma glutathione peroxidase (GPx3), gastrointestinal GPx2, phospholipid hydroperoxide-reducing GPx4, oilfactory epithelial GPx6, and also selenoprotein P (SeP), $15 \mathrm{kDa}$ selenoprotein (Sep15), three iodothyronine deiodinases, three thioredoxin ( $\mathrm{TrR}$ ) reductases and additional selenoproteins (6).

Differences in the expression of selenoprotein mRNAs can reflect dietary Se supply. Both $G P x 1$ and $G P \times 3$ transcript levels rapidly decrease in cases of Se deficiency, whereas GPx2 mRNA and GPX4 mRNA levels are fairly resistant to deficiency $(7,8)$. This hierarchy of selenoproteins with respect to Se status may be important in the formation of different tumours, especially since selenoproteins show tissue-specific expression profiles (8). In vitro and animal studies suggest that low levels of selenoprotein transcripts in response to low Se concentrations have been associated with loss of mRNA stability, and degradation during non-sense-mediated decay (NMD) process (7, 8). Of the 25 known human selenoprotein mRNAs, 14 are thought to be sensitive to NMD (9). Single nucleotide polymorphisms, potentially modifying transcription processes, have also been observed in genes encoding for selenoproteins (10).

Special emphasis has recently been placed on the application of circulating white blood cell (WBC) transcriptome patterns. Transcriptomic studies clearly 
show that various cluster genes can be significantly expressed in WBCs (11). This allows genomic fingerprints to be easily obtained to explore the different responses to nutritional status and environmental exposure. Gene expression patterns may be useful for defining biological processes associated with human health and disease. Evenson et al. (12) found that mRNA concentrations of rat selenoproteins in whole blood were comparable to concentrations detected in the major organs. Decreased rat GPx1 mRNA concentrations in rat blood and liver under conditions of dietary deficiency of Se indicated that WBC mRNA concentrations could be a biomarker of Se exposure in rats. Lampe et al. (13) showed that active exposure to tobacco smoke is associated with a biological relevant mRNA expression signature. Therefore, we investigated human (h)GPX1, hGPx3, hSep15, and $h S e P 1$ transcript concentrations in circulating leukocytes to determine whether gene expression in healthy individuals differs from that in patients with bladder cancer who present with different smoking habits. Also, we wished to determine if there is an impact of Se status and GPX1 Pro198Leu, Sep15 $1125 \mathrm{G} / \mathrm{A}$ genetic polymorphism on expression of selenoprotein mRNA.

\section{Materials and methods}

\section{Study population}

Male patients with bladder cancer and healthy male controls were recruited from the Department of Urology, Medical University, Lodz, and from the Nofer Institute of Occupational Medicine, Lodz, respectively. All patients were not undergoing intravenous and/or intrabladder chemotherapy administration and with transurethral resection. Patients presented with transitional cell carcinoma (TCC) of the urinary bladder. Cases $(n=33)$ and controls $(n=47)$ were selected with respect to smoking habits in order to provide similar numbers of smokers and non-smokers. The non-smokers included those who had never smoked and those who previously smoked, but quit smoking $\geq 5$ years prior to entering the study. The study participants completed a questionnaire that provided information on demographic characteristics including age, body mass index (BMI) and smoking history. The characteristics of the study population are presented in Table 1. The Regional Ethics Committee for Scientific Research approved the study protocol, and a written informed consent was obtained from all participants.

\section{Se status}

Blood samples were collected into Venoject ${ }^{\circledR}$ heparinized (lithium heparin) test tubes, free from trace elements, for determination of Se status. Blood was also collected into EDTA tubes for isolation of RNA and DNA. Plasma Se concentrations were measured according to Neve et al. (14) using graphite furnace atomic absorption spectrometry (Solaar 989 QZ apparatus, Unicam, Thermo Scientific, Warsaw, Poland). The method was validated using reference material consisting of lyophilized human reference serum samples of Seronorm ${ }^{\text {TM }}$ (Nycomed Pharma AS, Oslo, Norway). Red blood cell (RBC) and plasma GPx activities were measured spectrophotometrically according to the method of Paglia and Valentine (15) with modification by Hopkins and Tudhope (16).

\section{RNA and DNA isolation and cDNA synthesis}

Total RNA and genomic DNA were isolated from whole blood using the OIAamp RNA Blood Mini Kit and QIAamp DNA Blood Mini Kit (Qiagen, Syngen Biotech, Wroclaw, Poland), respectively, according to the manufacturer's instructions. The concentration and purity of isolated RNA and DNA were determined spectrophotometrically. cDNA was synthesized on 250 ng RNA with Omniscript RT Kit (Qiagen, Syngen Biotech, Poland), oligo $\mathrm{dT}_{15-18}$ primer and RNase-free DNase I (Promega, Symbios, Gdansk, Poland).

\section{Selenoprotein mRNAs expression}

Expression of the $h G P x 1, h G P \times 3, h S e p 15$ and $h S e P 1$ genes was quantified with the iQ5 real-time PCR detection system (Bio-Rad, Warsaw, Poland) using glyceraldehyde 3-phosphate dehydrogenase ( $h G A P D H)$ as the endogenous control. This allowed for stable expression levels of RNA isolated from peripheral blood leukocytes. Forward and reverse primers for target genes and $\operatorname{TaqMan}^{\circledR}$ probes were designed

Table 1 Demographics of the study population.

\begin{tabular}{|c|c|c|c|}
\hline & Controls $(n=47)$ & Cancer $(n=33)$ & p-Value \\
\hline Age, years & $49.1 \pm 17.4$ & $67.6 \pm 9.7$ & $<0.0001$ \\
\hline \multicolumn{4}{|l|}{ Smoking habit } \\
\hline Yes & $13(27.7 \%)$ & $13(39.4 \%)$ & \multirow[t]{2}{*}{0.335} \\
\hline No & $34(72.3 \%)^{a}$ & $20(60.6 \%)^{b}$ & \\
\hline $\mathrm{BMI}^{\mathrm{c}}, \mathrm{kg} / \mathrm{m}^{2}$ & $25.1 \pm 4.0$ & $26.7 \pm 3.3$ & 0.120 \\
\hline Se, ng/mL plasma & $54.3 \pm 14.6$ & $50.5 \pm 23.0$ & 0.282 \\
\hline GPx1, U/L plasma & $22.9 \pm 3.7$ & $22.0 \pm 7.2$ & 0.434 \\
\hline GPx3, U/g Hb & $0.200 \pm 0.040$ & $0.167 \pm 0.036$ & 0.0008 \\
\hline \multicolumn{4}{|l|}{$G P \times 1$} \\
\hline Pro198Pro & $27(58.7 \%)^{\mathrm{d}}$ & $13(39.4 \%)$ & \multirow[t]{3}{*}{0.058} \\
\hline Pro198Leu & $18(39.1 \%)$ & $15(45.5 \%)$ & \\
\hline Leu198Leu & $1(2.2 \%)$ & $5(15.1 \%)$ & \\
\hline \multicolumn{4}{|l|}{ Sep 15} \\
\hline $1125 \mathrm{G} / \mathrm{G}$ & $20(43.5 \%)$ & $21(63.6 \%)$ & \multirow[t]{3}{*}{0.141} \\
\hline $1125 \mathrm{G} / \mathrm{A}$ & $23(50.0 \%)$ & $9(27.3 \%)$ & \\
\hline $1125 \mathrm{~A} / \mathrm{A}$ & $3(6.5 \%)$ & $3(9.1 \%)$ & \\
\hline
\end{tabular}

aThe non-smoking group includes 2 ex-smokers, who quit smoking $\geq 5$ years before the investigation; ${ }^{\text {bthe non-smoking group }}$ includes 15 ex-smokers, who quit smoking $\geq 5$ years before the diagnosis of cancer, smoking history of 1 individual is missing; cBMI data on 3 controls are missing; ${ }^{\mathrm{d}} G P x 1$ genotyping data for 1 control is missing. $\mathrm{Hb}$, hemoglobin. 
with Beacon Designer 7.0 (PREMIER Biosoft Int, Bio-Rad, Poland) according to the GenBank ${ }^{\circledR}$ genetic sequence database. The amplicon sequence complied with exon-exon boundaries, whenever possible (Table 2). All samples were amplified in triplicate. Samples from the controls and cancer patients were amplified simultaneously on the same plate. Calculated PCR efficiencies were: $99 \%$ for $h G P \times 3,97 \%$ for $h S e P 1$ and $95 \%$ for $h G P x 1, h$ Sep 15 and $h G A P D H$. mRNA expression data were evaluated by means of two calculation methods. Reference gene-normalized relative quantitation with efficiency correction was calculated using Q-Gene, a Microsoft Excel ${ }^{\circledR}$-based software application coded in Visual Basic (17). Calibrator-normalized relative expression for estimating up- and down-regulation of gene expression in the patients with bladder cancer was calculated using REST 2005 Software, Version: 1.9.10 (The Gene Quantification website, www.gene-quantification.info).

\section{Genotyping}

GPX1 Pro198Leu (rs 1050450) primers and probes were designed with Beacon Designer 7.0 (PREMIER Biosoft Int, Bio-Rad, Poland) according to the GenBank ${ }^{\circledR}$ genetic sequence database. Genetic polymorphism was analysed using Molecular Beacon Real-Time PCR. Oligonucleotide sequences for $\mathrm{PCR}$ primers and fluorescent probes were: forward primer 5'-TGACGGTGTGCCCCTACG-3', and reverse primer 5'-CCGAGACAGCAGCACTGC-3', probe C 5'-(6-Fam) CGCGATCAGGCACAGCTGGGCCCTTGAGACGATCGCG (Dabcyl)-3', probe $T 5^{\prime}-(\mathrm{Hex})$ CGCGATCAGGCACAGCTGAGCCCTTGAGACGATCGCG (Dabcyl)-3'. Sep15 1125G/A polymorphism (rs 5859) was analysed using the PCR-RFLP assay. Oligonucleotide sequences for $\mathrm{PCR}$ primers were: forward 5'-GCCTGCTCCTCAGAGTCTC- $3^{\prime}$ and reverse $5^{\prime}-$ AAACATGAAAGAACAAACCAGAAG-3'. The amplicons were digested with FspBI (Fermentas, ABO, Gdansk, Poland) and the digestion products (360 bp, $198 \mathrm{bp}, 162 \mathrm{bp}$ ) were analysed in $1.5 \%$ agarose gel using Molecular Imager Gel Doc and ChemiDoc Systems and Quantity One software (Bio-Rad, Poland).

\section{Statistical analysis}

Statistical analyses were performed with GraphPad Prism ${ }^{\circledR}$ Version 5.01 (GraphPad Software, Inc., San Diego, CA, USA; www.graphpad.com). For comparison of the study groups, an unpaired t-test, one-way analysis of variance (for biochemical analyses) and the Mann-Whitney U-test, the Kruskal-Wallis test (for gene expression analyses) and Fisher's exact test were used. Correlations were assessed using Pearson (for biochemical analyses) or Spearman (for gene expression analyses) analysis. For all the tests, a two-sided $p<0.05$ was used for determining statistical significance.

\section{Results}

Smoking habits and BMI were similar in both groups. Thirty-three patients with TCC of the urinary bladder, with different grading $(\mathrm{G})$ and staging $(\mathrm{T})$, were examined. The majority of bladder cancer cases were characterized by low degree of neoplasm (G1) and clinical progression (T1) $(n=14$ and $n=24$, respectively). Eight patients with grade $\mathrm{G} 2$ and nine patients with grade G3 presented with a high degree of neoplasia. Invasive characteristics of bladder tumours were seen in four patients with stage T2 and three patients with grade T3. Histopathological data for grading two of the patients was missing.

\section{Gene expression}

All the subjects expressed measurable selenoprotein mRNA concentrations in blood leukocytes, with large inter-individual variations in gene expression. The highest concentration of gene transcripts in circulating leukocytes was observed for the $h G P \times 1$ and $h$ Sep15 genes. The lowest concentration was attributable to the $h G P \times 3$ and $h S e P 1$ genes. We observed significant down-regulation of $h G P x 1, h G P \times 3, h \operatorname{Sep} 15$ and SeP1 mRNA in leukocytes from patients with bladder cancer when compared to controls. hSeP1 and $h G P \times 3$ showed the highest down-regulation in the bladder cancer group compared to controls, with mean factors of 0.480 and 0.546 , respectively. hSep 15 showed down-regulation in the bladder cancer group, compared to the control group, by a mean factor of

Table 2 Oligonucleotide primers and $\operatorname{TaqMan}^{\circledR}$ probes used for real-time PCR.

\begin{tabular}{|c|c|c|c|}
\hline Gene & GI number & Primers and probes sequence ${ }^{a}$ & $\begin{array}{l}\text { Amplicon } \\
\text { size, bp }\end{array}$ \\
\hline$h G P \times 1$ & 41406083 & $\begin{array}{l}\text { F-GCATCAGGAGAACGCCAAGAAC } \\
\text { R-CGCAGGAAGGCGAAGAGAGG } \\
\text { P-CCCGCACCGTTCACCTCGCACTTC }\end{array}$ & 144 \\
\hline$h G P \times 3$ & 89903006 & $\begin{array}{l}\text { F-GAACTCAGAGATCCTTCCTACCC } \\
\text { R-CTGCTCTTTCTCTCCATTGACATC } \\
\text { P-CCGACCAGGTGGAGGCTTTGTCCC }\end{array}$ & 106 \\
\hline hSep15 & 42741647 & $\begin{array}{l}\text { F-TTTGGGCTACGGTTGTTGTTG } \\
\text { R-AGTTGCTAGAAAAGCCTAACTCTC } \\
\text { P-TGCCTCCGATGAAAACTCTGCCCC }\end{array}$ & 103 \\
\hline hSepP1 & 62530390 & $\begin{array}{l}\text { F-GCCTTCATCACCACCATAAGC } \\
\text { R-ATACATCTCTTTCGACAGAGCTTC } \\
\text { P-TCAGCATAGGCAGGGTCACCCAGA }\end{array}$ & 121 \\
\hline$h G A P D H$ & 83641890 & $\begin{array}{l}\text { F-GGACCTGACCTGCCGTCTAG } \\
\text { R-TGTAGCCCAGGATGGCCCTTG } \\
\text { P-CCTCCGACGCCTGCTTCACCACCT }\end{array}$ & 101 \\
\hline
\end{tabular}

a F, forward 5'-3'; R, reverse primer 5'-3'; P, TaqMan probe 5'-3' (6-FAM-TAMRA); h, human; GPx1, cytosolic glutathione peroxidase; GPx3, plasma glutathione peroxidase; Sep15, 15 kDa selenoprotein; SeP1, selenoprotein P; GAPDH, glyceraldehyde 3-phosphate dehydrogenase. 
Table 3 Differences in selenoprotein mRNA expression normalised to $h G A P D H^{a}$ and selenoprotein mRNA relative expression $^{\mathrm{b}}$ from leukocytes of patients with bladder cancer and controls.

\begin{tabular}{|c|c|c|c|c|c|}
\hline Gene & Controls, $n=47$ & Cancer, $\mathrm{n}=33$ & $p-V_{a l u e}^{a}$ & Expression ratio (SE) & $p-$ Value $^{b}$ \\
\hline \multicolumn{6}{|l|}{$h G P \times 1$} \\
\hline Median & 0.435 & 0.372 & 0.190 & $0.778(0.360-1.637)$ & 0.067 \\
\hline $25 \%$ percentile & 0.247 & 0.265 & & & \\
\hline $75 \%$ percentile & 0.718 & 0.425 & & & \\
\hline Mean $\pm S D$ & $0.683 \pm 0.705$ & $0.404 \pm 0.222$ & & & \\
\hline \multicolumn{6}{|l|}{$h G P \times 3$} \\
\hline Median & 0.0018 & 0.0012 & 0.019 & $0.546(0.198-1.641)$ & 0.002 \\
\hline $25 \%$ percentile & 0.0009 & 0.0006 & & & \\
\hline $75 \%$ percentile & 0.0031 & 0.0019 & & & \\
\hline Mean \pm SD & $0.0026 \pm 0.0028$ & $0.0013 \pm 0.0010$ & & & \\
\hline \multicolumn{6}{|l|}{ hSep15 } \\
\hline Median & 0.205 & 0.187 & 0.01 & $0.592(0.469-1.082)$ & $<0.0001$ \\
\hline $25 \%$ percentile & 0.168 & 0.132 & & & \\
\hline $75 \%$ percentile & 0.283 & 0.210 & & & \\
\hline Mean \pm SD & $0.279 \pm 0.227$ & $0.173 \pm 0.078$ & & & \\
\hline \multicolumn{6}{|l|}{$h S e P 1$} \\
\hline Median & 0.0023 & 0.0013 & $<0.0001$ & $0.480(0.246-0.901)$ & $<0.0001$ \\
\hline $25 \%$ percentile & 0.0017 & 0.0009 & & & \\
\hline $75 \%$ percentile & 0.0038 & 0.0019 & & & \\
\hline Mean $\pm S D$ & $0.0045 \pm 0.0068$ & $0.0019 \pm 0.0020$ & & & \\
\hline
\end{tabular}

${ }^{\text {a }}$ Reference gene-normalised relative quantification with efficiency correction; ${ }^{b}$ calibrator-normalised relative expression.

0.592 and $h G P x 1$ by a mean factor of 0.778 (Table 3 ). We did not observe differences in expression of the four selenoprotein encoding genes in patients with TCC of the bladder and non-invasive (T1) and invasive $(\mathrm{T} 1+\mathrm{T} 3)$ characteristics. However, expression of selenoprotein mRNA in leukocytes of patients with TCC gradually increased with tumour grade, showing statistical significance for $h G P x 3(p=0.023)$ and $h$ Sep 15 $(p=0.008)$ (Figure 1B and C). Comparison of $\mathrm{G} 1$ and
G3 tumour grades showed significant up-regulation of hGPX3 (2.7-fold; $\mathrm{p}=0.045$ ) and hSep15 (2.4-fold; $\mathrm{p}=0.040$ ) (data not shown). In the control group, significant correlation between expression levels of the selenoproteins ( $h G P \times 1 / h G P \times 3, h G P \times 1 / h S e p 15$, $h G P x 1 / h S e P 1, h G P x 3 / h S e p 15, h G P x 3 / h S e P 1, h S e p 15 /$ $h S e P 1)$ were found. However, in patients with cancer, the only significant correlation was found between $h G P x 3$ and $h \operatorname{Sep} 15(\mathrm{r}=0.350, \mathrm{p}=0.05)$ (Table 4).
A

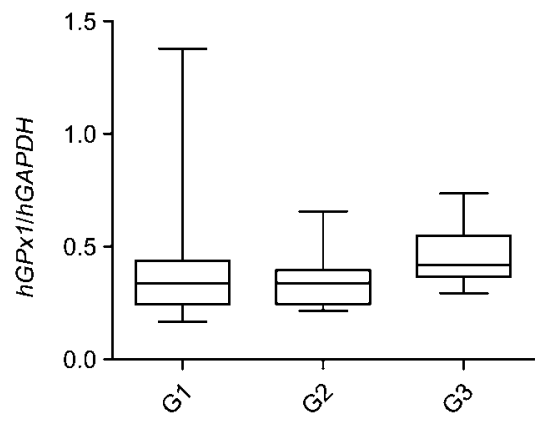

B

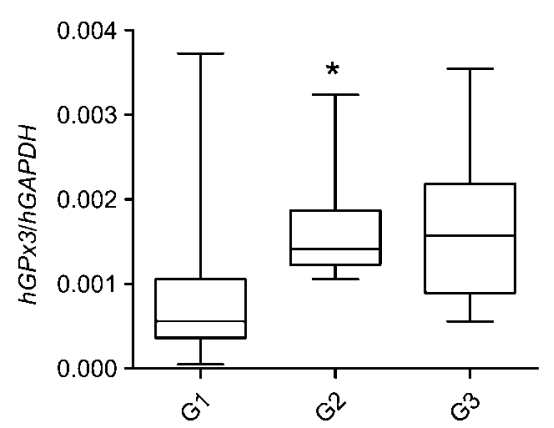

C

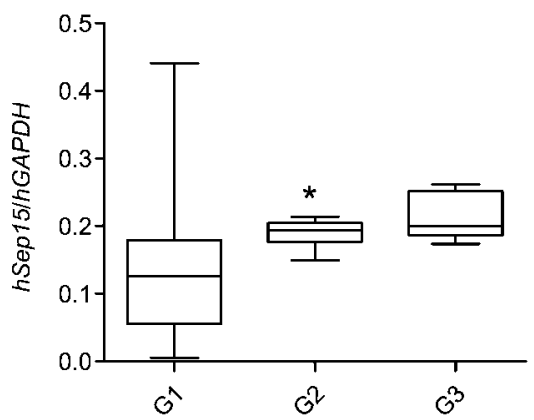

D

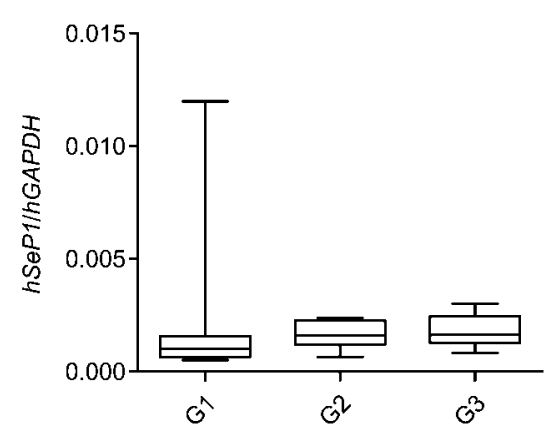

Figure 1 Selenoprotein mRNA expression normalised to $h G A P D H$ in leukocytes in relation to different grades of bladder cancer ( $\mathrm{G} 1, \mathrm{n}=14 ; \mathrm{G} 2, \mathrm{n}=8 ; \mathrm{G} 3, \mathrm{n}=9$ ).

(A) mRNA $h G P x 1, \mathrm{p}=0.124$; (B) mRNA $h G P x 3, \mathrm{p}=0.023^{*}$; (C) mRNA $h$ Sep 15, $\mathrm{p}=0.008^{*}$; (D) mRNA $h S e P 1, \mathrm{p}=0.114$. 
Table 4 Correlation between selenium status and selenoprotein mRNA expression normalised to $h G A P D H$ in leukocytes from patients with bladder cancer and controls.

\begin{tabular}{|c|c|c|c|c|}
\hline \multirow[t]{2}{*}{ Correlation } & \multicolumn{2}{|c|}{ Controls, $n=47$} & \multicolumn{2}{|c|}{ Cancer, $n=33$} \\
\hline & $\mathrm{r}$ & $\mathrm{p}$-Value & $r$ & $\mathrm{p}$-Value \\
\hline \multicolumn{5}{|l|}{ Se status } \\
\hline $\mathrm{GP} \times 1 / \mathrm{Se}$ & 0.114 & 0.444 & 0.334 & 0.057 \\
\hline $\mathrm{GP} \times 3 / \mathrm{Se}$ & 0.468 & 0.0009 & 0.343 & 0.051 \\
\hline \multicolumn{5}{|c|}{ Selenoprotein mRNAs expression and Se status } \\
\hline$h G P \times 1 / \mathrm{Se}$ & 0.180 & 0.226 & 0.001 & 0.995 \\
\hline$h G P \times 3 / \mathrm{Se}$ & 0.178 & 0.230 & -0.061 & 0.734 \\
\hline hSep 15/Se & 0.101 & 0.501 & -0.007 & 0.710 \\
\hline$h \mathrm{SeP} 1 / \mathrm{Se}$ & 0.159 & 0.287 & 0.069 & 0.702 \\
\hline$h G p \times 1 / G P x 1$ & -0.223 & 0.132 & 0.133 & 0.459 \\
\hline$h G P \times 3 / G P x 3$ & 0.006 & 0.967 & -0.018 & 0.922 \\
\hline \multicolumn{5}{|c|}{ Selenoprotein mRNAs expression } \\
\hline$h G P \times 1 / h G P \times 3$ & 0.797 & $<0.0001$ & 0.029 & 0.871 \\
\hline$h G P \times 1 / h \operatorname{Sep} 15$ & 0.768 & $<0.0001$ & 0.316 & 0.074 \\
\hline$h G P \times 1 / h S e P 1$ & 0.425 & 0.003 & 0.186 & 0.299 \\
\hline$h G P \times 3 / h \operatorname{Sep} 15$ & 0.791 & $<0.0001$ & 0.350 & 0.05 \\
\hline$h G P \times 3 / h S e P 1$ & 0.453 & 0.001 & 0.279 & 0.116 \\
\hline hSep15/hSeP1 & 0.583 & $<0.0001$ & 0.455 & 0.008 \\
\hline
\end{tabular}

\section{Se status}

Se status in the study participants was assessed using plasma Se concentration, GPx3 activity, and GPx1 activity in RBCs. In both cases and controls, neither Se concentration or GPX1 activity differed significantly. Plasma GPx3 activity was significantly lower $(p<0.0008)$ in patients with bladder cancer compared with controls (Table 1). Se status did not differ between patients with bladder cancer with different tumour grades (G1, G2 and G3) and characteristics of muscle invasion (T1 and T2+T3) (data not shown). There was no significant correlation between Se concentrations and GPx activities in both study groups. A significant association between plasma Se concentration and GPx3 activity in plasma ( $r=0.468$; $p<0.0009$ ) was found in controls (Table 4). An analysis performed to assess the relationship between selenoprotein mRNA concentrations and Se status, indicated by Se concentrations and plasma activity of GPx1 RBC and GPx3, revealed no significant correlation in either of the groups.

\section{Genetic polymorphism}

The distribution of GPX1 Pro198Leu and Sep15 $1125 \mathrm{G} / \mathrm{A}$ genotypes in the controls and patients with bladder cancer did not differ significantly (Table 1). We found no effect of genetic polymorphisms of GPX1 and Sep15 on Se status or selenoprotein mRNA concentrations (data not shown).

\section{Impact of smoking on Se status and gene expression}

To investigate the potential impact of tobacco smoking on Se status and selenoprotein gene expression, we divided both groups into non-smokers and smokers. There were no differences between selenoprotein transcript concentrations in bladder cancer patients, relative to smoking habits. However, in the control group, hGPx1, hGPx3 and $h$ Sep 15 expression was significantly lower in smokers compared with nonsmokers. hSep 15 showed the highest down-regulation in smokers compared with non-smokers by a mean factor of 0.645 . $h G P x 3$ was down-regulated by a mean factor of 0.457 , and $h G P x 1$ by a mean factor of 0.386 (Table 5). Comparison between non-smoking controls and cancer patients showed significant downregulation of expression of all the selenoprotein encoding genes in leukocytes in patients with bladder cancer, while cancer patients who smoked presented with significantly lower expression of $h G P x 1$ and hSep15 compared with controls that smoked. GPx3 activity was significantly lower in both non-smoking and smoking patients with cancer compared to their respective control groups (Table 5). The observed correlations between the expression level of all the selenoprotein mRNAs in the control group were almost entirely related to non-smokers (Table 6).

\section{Discussion}

Se and selenoproteins are widely implicated in the aetiology of cancer, suggesting several hypothesis for the anticarcinogenic activity of this trace element. Se and selenoprotein concentrations in blood or blood compartments were lower in cancer patients than in controls (4). The mechanism of the anticarcinogenic activity of $\mathrm{Se}$ in bladder neoplasms can be explained by a possible direct and indirect effect on bladder mucosa, via plasma, reducing the concentration of carcinogens. In this study, plasma Se concentration and GPx1 activity did not differ in patients with bladder cancer and controls.

Data concerning selenoprotein mRNA expression in malignant and non-malignant tissue still provides insufficient information about bladder tumours. There are no good data on the levels of different selenoprotein transcript concentrations in tumours and benign 
Table 5 Differences in selenoprotein mRNA expression normalised to $h G A P D H^{\mathrm{a}}$, selenoprotein mRNA relative expression ${ }^{\mathrm{b}}$ and selenium status in patients with bladder cancer and controls with respect to smoking status.

\begin{tabular}{|c|c|c|c|c|c|}
\hline & $\begin{array}{l}\text { Non-smokers, } \\
\mathrm{n}=34 \\
\text { Mean } \pm \mathrm{SD}\end{array}$ & $\begin{array}{l}\text { Smokers, } \\
\mathrm{n}=13 \\
\text { Mean } \pm \mathrm{SD}\end{array}$ & $p-$ Value $^{a}$ & Expression ratio (SE) & $p-$ Value $^{\mathrm{b}}$ \\
\hline \multicolumn{6}{|l|}{ Controls } \\
\hline $\mathrm{Se}, \mathrm{ng} / \mathrm{mL}$ & $56.0 \pm 12.9$ & $50.0 \pm 18.23$ & 0.069 & & \\
\hline GPx1, U/g Hb & $22.4 \pm 3.3$ & $24.2 \pm 4.4$ & 0.094 & & \\
\hline GPx3, U/L plasma & $0.200 \pm 0.041$ & $0.201 \pm 0.037$ & 0.943 & & \\
\hline$h G P \times 1$ & $0.813 \pm 0.732$ & $0.342 \pm 0.508$ & $<0.0001$ & $0.386(0.201-1.243)$ & $<0.0001$ \\
\hline$h G P \times 3$ & $0.0031 \pm 0.0031$ & $0.0012 \pm 0.0016$ & 0.0002 & $0.457(0.238-1.878)$ & $<0.0001$ \\
\hline hSep 15 & $0.293 \pm 0.162$ & $0.240 \pm 0.0350$ & 0.0001 & $0.645(0.456-0.914)$ & $<0.0001$ \\
\hline \multirow[t]{2}{*}{$h \mathrm{SeP1}$} & $0.0042 \pm 0.0053$ & $0.0053 \pm 0.0100$ & 0.529 & $0.934(0.465-2.018)$ & 0.716 \\
\hline & $\begin{array}{l}\text { Non-smokers, } \\
\mathrm{n}=20 \\
\text { Mean } \pm \mathrm{SD}\end{array}$ & $\begin{array}{l}\text { Smokers, } \\
\mathrm{n}=13 \\
\text { Mean } \pm \mathrm{SD}\end{array}$ & $p-$ Value $^{a}$ & Expression ratio (SE) & $p-$ Value $^{b}$ \\
\hline \multicolumn{6}{|l|}{ Cancer } \\
\hline Se, ng/mL & $48.6 \pm 22.3$ & $53.5 \pm 24.6$ & 0.672 & & \\
\hline $\mathrm{GPx} 1, \mathrm{U} / \mathrm{g} \mathrm{Hb}$ & $22.1 \pm 6.6$ & $21.9 \pm 8.4$ & 0.839 & & \\
\hline GPx3, U/L plasma & $0.172 \pm 0.035^{c}$ & $0.164 \pm 0.038^{c}$ & 0.495 & & \\
\hline$h G P \times 1$ & $0.343 \pm 0.089^{c}$ & $0.497 \pm 0.321^{c}$ & 0.246 & $1.252(0.660-2.380)$ & 0.300 \\
\hline$h G P \times 3$ & $0.0015 \pm 0.0010^{c}$ & $0.0012 \pm 0.0009$ & 0.387 & $0.924(0.265-2.508)$ & 0.847 \\
\hline hSep15 & $0.156 \pm 0.069^{c}$ & $0.200 \pm 0.087^{c}$ & 0.191 & $1.526(0.809-1.654)$ & 0.239 \\
\hline$h \mathrm{SeP} 1$ & $0.0018 \pm 0.0025^{c}$ & $0.0020 \pm 0.0014$ & 0.146 & $1.356(0.781-2.746)$ & 0.230 \\
\hline
\end{tabular}

${ }^{a}$ Reference gene-normalised relative quantification with efficiency correction; ${ }^{b}$ calibrator-normalised relative expression;

${ }^{c}$ statistically significant differences $(p<0.05)$ between controls and cancer patients. Hb, hemoglobin.

Table 6 Correlation between selenoprotein mRNA expression normalised to $h$ GAPDH from leukocytes of controls in relation to smoking status.

\begin{tabular}{|c|c|c|c|c|}
\hline \multirow[t]{2}{*}{ Correlation } & \multicolumn{2}{|c|}{ Non-smokers, $\mathrm{n}=34$} & \multicolumn{2}{|c|}{ Smokers, $n=13$} \\
\hline & $r$ & $p$-Value & $r$ & $\mathrm{p}$-Value \\
\hline$h G P \times 1 / h G P \times 3$ & 0.651 & $<0.0001$ & 0.388 & 0.190 \\
\hline hGPx $1 / h \operatorname{Sep} 15$ & 0.559 & 0.0006 & 0.418 & 0.155 \\
\hline$h G P \times 1 / h S e P 1$ & 0.508 & 0.002 & 0.226 & 0.459 \\
\hline$h G P \times 3 / h \operatorname{Sep} 15$ & 0.614 & 0.0001 & 0.720 & 0.006 \\
\hline$h G P \times 3 / h S e P 1$ & 0.560 & 0.0006 & 0.187 & 0.541 \\
\hline hSep15/hSeP1 & 0.775 & $<0.0001$ & 0.264 & 0.384 \\
\hline
\end{tabular}

samples. It is presumed that tissue Se status, as well as genetic and epigenetic alterations such as deletions and hypermethylation can influence mRNA concentrations of selenoproteins $(18,19)$. Our findings may support the hypothesis that there is low expression of selenoprotein mRNAs in neoplasms. We found that leukocytes from patients with bladder cancer showed significant down-regulation in $h G P x 1$, $h G P x 3, h S e p 15$ and $h S e P 1$ expression compared to leukocytes from controls. The results from patients with TCC of the urinary bladder showed up-regulation of tissue GPx in cases with different grades of tumour and invasive characteristics (20). Our findings concerning $h G P \times 3$ and $h$ Sep 15 expression in leukocytes of patients with bladder cancer, which correlated with tumour grade, add to the data concerning expression of selenoprotein genes in peripheral leukocytes of patients with different grades of bladder TCC.

It is well known that selenoproteins are unevenly distributed amongst different tissues. The most ubiquitous is GPX1, Sep15 is found primarily in the liver and prostate, kidney is the main source of GPx3 and SeP is synthesised in the liver. Different selenoprotein mRNA expression levels may be associated with the hierarchy of selenoproteins in response to Se status (8). The present study indicates that there is a large inter-individual variation in selenoprotein gene expression in human circulating leukocytes with specific expression patterns. The observed higher expression of mRNA of $h G P x 1$ and $h$ Sep 15 in leukocytes compared with $h G P x 3$ and $h S e P$ may also suggest a first-line of action for GPx1 and Sep15 in antioxidant defences in WBCs. Inter-individual differences in selenoprotein expression in leukocytes, observed in our study, can be associated with heterogeneous WBC populations used in this investigation, including lymphocytes, monocytes, and granulocytes. Each subset of leukocytes presents a unique pattern of gene expression related to its specific function (21). Different expression of selenoprotein mRNAs in patients with cancer of the urinary bladder and controls may reflect the relative proportions of specific WBC subpopulations. In addition, the results of our study did not confirm a functional significance for GPX1 Pro198Leu and Sep15 1125G/A genetic polymorphisms, which could potentially modify Se status and/or $h G P x 1$ and $h$ Sep 15 expression in peripheral leukocytes. To date, genetic polymorphisms within 
selenoproteins have been found in $h G P \times 1, h G P \times 3$, $h$ Sep 15, and $h S e P 1$ genes. The functional effect of these polymorphisms was confirmed primarily in studies of cell cultures (10).

Some studies have indicated that specific gene transcription in circulating blood leukocytes is associated with cigarette smoking $(13,22,23)$. It has been observed that smoking can reduce Se concentrations within the body, due to possible interactions with arsenic that is present in tobacco smoke (23). We did not find significant differences in plasma Se concentrations, RBC GPx1 or plasma GPx3 activity between non-smokers and smokers with bladder cancer and controls. In TCC of the bladder, there were no differences in selenoprotein gene expression between nonsmokers and smokers. However, in the control group, $h G P x 1, h G P x 3$ and $h$ Sep15 showed significantly higher expression in leukocytes from non-smokers compared with expression leukocytes from smokers. Moreover, significant correlation between expression levels of all the studied selenoprotein mRNAs were generally seen in non-smoking healthy controls.

A growing number of studies have investigated different populations of WBC transcriptome patterns. This readily accessible human biological material can be easily used and is supposed to be a biomarker of nutritional status $(24,25)$. The study performed on rats by Evenson et al. (12) indicated that WBC $r G P \times 1$ mRNA concentrations can be a useful biomarker of the effects of Se exposure. However, our results did not confirm the hypothesis that the expression of selenoprotein mRNA in circulating leukocytes can reflect Se status. Correlation between mRNA $h G P x 1$, $h G P x 3, h S e p 15, h S e P 1$ and Se status showed no significant association in patients with TCC of the urinary bladder or healthy controls. Recent results by RavnHaren et al. $(23,24)$ also indicated lack of alterations in selenoprotein mRNA expression in WBCs after short- and long-term supplementation with Se. Following one week of non-organic or organic forms of Se supplementation in healthy young Danish men, there were no differences in expression of GPX1, cytosolic TrR1 and SeP1 in leukocytes.

In conclusion, significant differences in expression of $h G P x 1, h G P x 3, h S e p 15$ and SeP1 in leukocytes of patients with bladder cancer when compared with controls appear to be associated with smoking status. Moreover, in non-smoking controls, a significant positive relationship between expression of all the studied genes was observed. We did not find a functional significance for GPx1 and Sep15 genetic polymorphisms with respect to Se status or gene expression in leukocytes. Transcript concentrations in circulating leukocytes of bladder cancer patients and controls did not reveal a potential impact of Se status on expression of selenoproteins. Differences in age and the relatively low number of study participants were limitations of our study. Despite this, the use of WBCs, including leukocytes, warrants further investigations in a larger group of patients of both genders with different baseline Se status, and in patients with different types of neoplasms. The elucidation of the potential interactions between selenoprotein transcript concentrations and selenoprotein concentrations and activity, in relation to several genetic polymorphisms of selenoproteins, should be also included.

\section{Conflict of interest statement}

The authors have made substantial contributions to the research in the various sections and have no conflict of interest to declare. The authors have not accepted any funding or support from an organization that may in any way gain or lose financially from the results of this study. The authors have not been employed by an organization that may in any way gain or lose financially from the results of this study.

\section{Acknowledgements}

This study was financially supported by the Ministry of Science and Higher Education (No. N N403 188434), internal grants IMP1.8/2007, IMP1.5/2007, IMP1.3/2007, and EU NoE Environmental Cancer Risk, Nutrition and Individual Susceptibility (ECNIS) No. 513943. The preliminary results of the study were presented at the Third ECNIS Annual Meeting held in Barcelona in 2008.

\section{References}

1. GLOBOCAN 2002 Database 2005. CancerMondial (IARC CancerBase No 5), http://www-dep.iarc.fr.

2. Zeegers MP, Kellen E, Buntinx F, van den Brandt PA. The association between smoking, beverage consumption, diet and bladder cancer: a systematic literature review. World J Urol 2004;21:392-401.

3. Rayman M. The argument for increasing selenium intake. Proc Nutr Soc 2002;61:203-15.

4. Gromadzinska J, Reszka E, Wasowicz W. Anticancerogenic activity of selenium - molecular mechanisms and epidemiological data. In: Akesson B, Mercke P, editors. Dietary vitamins, polyphenols, selenium and probiotics: biomarkers of exposure and mechanisms of anticarcinogenic action. WP9 ECNIS Report. Lodz: Nofer Institute of Occupational Medicine, 2007:91-114.

5. Brinkman M, Buntinx F, Muls E, Zeegers MP. Use of selenium in chemoprevention of bladder cancer. Lancet Oncol 2006;7:766-74.

6. Kryukov GV, Castellano S, Novoselov SV, Lobanov AV, Zehtab O, Guigo R, et al. Characterization of mammalian selenoproteomes. Science 2003;300:1439-43.

7. Weiss Sachdev S, Sunde RA. Selenium regulation of transcript abundance and translational efficiency of glutathione peroxidase-1 and -4 in rat liver. Biochem $\mathrm{J}$ 2001;357:851-8.

8. Meplan C, Pagmantidis V, Hesketh JE. Advances in selenoprotein expression: patterns and individual variations. In: Brigelius-Flohe R, Joost H-G, editors. Nutritional genomics. Impact on health and disease. Weinhem: Wiley-VCH Verlag GmbH \& Co. KgaA, 2006:132-58.

9. Squires JE, Stoytchev I, Forry E, Berry MJ. SBP2 binding affinity is a major determinant in differential selenoprotein mRNA translation and sensitivity to nonsensemediated decay. Mol Cell Biol 2007;27:7848-55.

10. Hesketh J. Nutrigenomics and selenium: gene expression patterns, physiological targets, and genetics. Annu Rev Nutr 2008;28:157-77. 
11. Visvikis-Siest S, Marteau J-B, Samara A, Berrahmoune $H$, Berangere $M$, Phister M. Peripheral blood mononuclear cells (PBMCs): a possible model for studying cardiovascular biology systems. Clin Chem Lab Med 2007; 45:1154-68.

12. Evenson JK, Wheeler AD, Blake S, Sunde RA. Selenoprotein mRNA is expressed in blood at levels comparable to major tissues in rats. J Nutr 2004;134:2640-5.

13. Lampe JW, Stepaniants SB, Mao M, Radich JP, Dai H, Linsley PS, et al. Signatures of environmental exposures using peripheral leukocyte gene expression: tobacco smoke. Cancer Epidemiol Biomarkers Prev 2004;13:44553.

14. Neve J, Chamart S, Molle L. Optimization of direct procedure for the determination of selenium in plasma and erythrocytes using Zeeman effect atomic absorption spectroscopy. In: Bratter P, Schramel P, editors. Analytical chemistry in medicine and biology, vol 4. Berlin: Walter de Gruyter 1987;4:349-58.

15. Paglia D, Valentine WN. Studies on the quantitative and qualitative characterisation of erythrocyte glutathione peroxidase. J Lab Clin Med 1967;70:158-69.

16. Hopkins J, Tudhope GR. Glutathione peroxidase in human red cells in health and disease. $\mathrm{Br} \mathrm{J}$ Haematol 1973;25:563-75.

17. Muller PY, Janovjak H, Miserez AR, Dobbie Z. Processing of gene expression data generated by quantitative realtime RT-PCR. Biotechniques 2002;2:1372-9.

18. Lodygin D, Epanchintsev A, Menssen A, Diebold J, Hermeking $\mathrm{H}$. Functional epigenomics identifies genes frequently silenced in prostate cancer. Cancer Res 2005; 65:4218-27.
19. Yu YP, Yu G, Tseng G, Cieply K, Nelson J, Defrances M, et al. Glutathione peroxidase 3, deleted or methylated in prostate cancer, suppresses prostate cancer growth and metastasis. Cancer Res 2007;67:8043-50.

20. Savic-Radojevic A, Mimic-Oka J, Pljesa-Ercegovac M, Opacic M, Dragicevic D, Kravic $T$, et al. Glutathione S-transferase-P1 expression correlates with increased antioxidant capacity in transitional cell carcinoma of the urinary bladder. Eur Urol 2007;52:470-7.

21. Whitney AR, Diehn M, Popper SJ, Alizadeh AA, Boldrick $\mathrm{JC}$, Relman DA, et al. Individuality and variation in gene expression patterns in human blood. Proc Natl Acad Sci USA 2003;100:1896-901.

22. van Leeuwen DM, van Agen E, Gottschalk RW, Vlietinck $\mathrm{R}$, Gielen $\mathrm{M}$, van Herwijnen $\mathrm{MH}$, et al. Cigarette smokeinduced differential gene expression in blood cells from monozygotic twin pairs. Carcinogenesis 2007;28:691-7.

23. Hulea SA, Olinescu R, Nita S, Crocnan D, Kummerow FA. Cigarette smoking causes biochemical changes in blood that are suggestive of oxidative stress: a case-control study. J Environ Pathol Toxicol Oncol 1995;14:173-80.

24. Ravn-Haren G, Bugel S, Krath BN, Hoac T, Stagsted J, Jorgensen $K$, et al. A short-term intervention trial with selenate, selenium-enriched yeast and seleniumenriched milk: effects on oxidative defence regulation. $\mathrm{Br}$ J Nutr 2008a;99:883-92.

25. Ravn-Haren G, Krath BN, Overvad K, Cold S, Moesgaard $\mathrm{S}$, Larsen $\mathrm{E}$, et al. Effect of long-term selenium yeast intervention on activity and gene expression of antioxidant and xenobiotic metabolizing enzymes in healthy elderly volunteers from the Danish Prevention of Cancer by Intervention by Selenium (PRECISE) Pilot Study. Br J Nutr 2008b;99:1190-8. 